\title{
O planejamento estratégico em uma organização de insumos agrícolas a partir de uma adaptação do Balanced Scorecard
}

\author{
Strategic planning in an organization of agricultural inputs from an adaptation of the \\ Balanced Scorecard
}

\begin{abstract}
Resumo
Em um cenário de acirrada competitividade, a capacidade das organizações para se preparar para possíveis imprevistos faz com que o planejamento estratégico seja cada vez mais necessário. Nesse sentido, esse artigo tem como propósito elaborar objetivos a serem alcançados com o planejamento estratégico a partir de uma adaptação baseada no modelo do Balanced Scorecard (BSC) em uma organização de insumos agrícolas. Para isso, adotou-se um estudo de caso exploratório-descritivo, caracterizando-se ainda como uma pesquisa participante, com a coleta de dados utilizando fontes primárias e secundárias. Entre os resultados obtidos, salienta-se que foi possível estabelecer os objetivos estratégicos a partir da visão organizacional, sendo descritos dentro das perspectivas do BSC a partir da formalização dos objetivos estratégicos, planos de ação e indicadores de desempenho. Deste modo, espera-se que a empresa consiga ser reconhecida pelos seus clientes e colaboradores nas suas relações dentro do agronegócio no Estado do Rio Grande do Sul.
\end{abstract}

Palavras-chave: Balanced Scorecard. Objetivos estratégicos. Planos de ação. Indicadores de desempenho.

\begin{abstract}
In a tough competitive scenario the capacity of organizations to prepare for possible unforeseen causes the strategic planning is increasingly necessary. Thus, this article aims to develop goals to be achieved with strategic planning from an adaptation based on the model of the Balanced Scorecard (BSC) in an organization of agricultural inputs. For this, was adopted a study of exploratory and descriptive case, characterizing even as a participatory research, with data collection using primary and secondary sources. Among the results we emphasize that it was possible to establish the strategic objectives from the organizational vision being described within the BSC perspectives from the formalization of the strategic objectives, action plans and performance indicators. Thus, it is expected that the company can be recognized by its customers and employees in their relations within the agribusiness in Rio Grande do Sul State.
\end{abstract}

Keywords: Balanced Scorecard. Strategic objectives. Action plans. Performance indicators.

Recebido: 15/04/2015 Aceito: 13/07/2015

Lorenzo Londero Pagliarin¹, Luis Felipe Dias Lopes², Lucas Charão Brito³, Flaviani Souto Bolzan Medeiros ${ }^{4}$ e Maíra Nunes Piveta ${ }^{5}$

${ }^{1}$ Universidade Federal de Santa Maria, Bacharel em Administração- pagliarinlorenzo@ gmail.com

${ }^{2}$ Universidade Federal de Santa Maria, Doutor em Engenharia de Produção - lflopes67@ yahoo.com.br

${ }^{3}$ Universidade Federal de Santa Maria, Doutorando em Administração- adm.lucascharao@hotmail.com

${ }^{4}$ Universidade Federal de Santa Maria, Mestre em Engenharia de Produção- flaviani.13@gmail.com

${ }^{5}$ Universidade Federal de Santa Maria, Graduanda em Administração- mairanpiveta@ gmail.com 


\section{Introdução}

$\mathrm{N}$ os últimos anos, com um ambiente volátil e instável, as organizações têm enfrentado diversos desafios no decorrer de suas trajetórias. Com uma intensa globalização e mercados onde a inovação e o acesso à informação passaram a ser diferenciais competitivos, torna-se necessário que as empresas estejam cada vez mais preparadas para aumento em termos de competição.

Com esse cenário, o planejamento estratégico torna-se uma ferramenta fundamental na medida em que provoca, se bem aplicado, modificações importantes dentro das empresas. Maccari, Lobosco e Souza (2012) reforçam que cada vez mais as empresas estão se convencendo da sua importância tanto da devida formulação de estratégias como também do seu uso.

No caso do presente trabalho, ele foi realizado em uma organização de insumos agrícolas que tem na soja seu carro chefe, responsável por $95 \%$ dos negócios da empresa. Sob esse enfoque, Silva, Lima e Batista (2011) afirmam que dentro do agronegócio a produção de soja tem se destacado como principal produto no setor, sendo também, uma das principais responsáveis pela difusão do conceito de agronegócio brasileiro.

Segundo dados do Ministério da Agricultura, Pecuária e Abastecimento (2015), a soja em grão foi o principal produto exportado do setor, correspondendo a 43,8\% do valor total exportado em produtos do agronegócio no mês de abril do corrente ano. Porém, a falta de infraestrutura, bem como a falta de planejamento na área são obstáculos que aumentam os custos e, consequentemente, reduzem a lucratividade de produtores e empresas atuantes no setor.

Com o passar do tempo, juntamente com o crescimento da referida empresa no mercado, constatouse que ter vantagens competitivas ou estar à frente, mesmo que apenas um passo, faz uma grande diferença em um mercado onde os produtos têm pouco ou nenhum valor agregado. Estas pequenas diferenças, porém, precisam ser identificadas previamente para que no futuro possam ser aproveitadas de tal forma que se tornem diferenciais competitivos.

Mesmo com um rápido crescimento, a organização de insumos agrícolas analisada nesse estudo mostra-se carente de uma orientação estratégica para que continue o seu processo de expansão no mercado. Por isso, o presente artigo tem como propósito elaborar objetivos a serem alcançados com o planejamento estratégico a partir de uma adaptação do modelo do Balanced Scorecard (BSC) na referida organização.

O estudo justifica-se em função da importância e necessidade de ter um direcionamento estratégico em toda e qualquer empresa, independentemente do porte e do ramo de atuação. No caso da empresa analisada, que tem como propósito crescer ainda mais no mercado, nesse momento, carece de uma orientação estratégica formal que possa conduzi-la ao crescimento de maneira sustentável e com objetivos claros e bem definidos.

\section{Referencial teórico}

\subsection{Balanced Scorecard}

Tavares (2010) define o Balanced Scorecard (BSC) como sendo uma ferramenta que permite realizar acompanhamento e adequada utilização das oportunidades de criação de valor para clientes, a partir de uma gestão eficiente de patrimônios tanto tangíveis quanto intangíveis. Essa forma de gestão estratégica, de acordo com Kaplan e Norton (2001), reflete o atual momento do mercado global, no qual $75 \%$ do valor de mercado das empresas é resultado de ativos intangíveis em poder da empresa, como, por exemplo, o capital humano, organizacional e da informação.

Assim, Kaplan e Norton (1997) afirmam que o BSC completa os indicadores financeiros de desempenho utilizados no passado. Segundo os autores, os objetivos e planos do BSC devem derivar da visão estratégica da empresa, tomando como base quatro perspectivas: financeira, clientes, processos internos e aprendizado e crescimento. Complementando, Willyerd (1997) acrescenta que o BSC está sendo utilizado cada vez mais como forma de medição do desempenho das empresas. A estratégia empresarial é avaliada segundo as perspectivas financeira, cliente e medidas operacionais.

Por sua vez, Zeus (2004) define o BSC como uma ferramenta de gestão empresarial que objetiva integrar e conectar todos os principais indicadores de desempenho utilizados dentro das empresas, buscando alcançar a qualidade máxima em todos os níveis organizacionais. Além disso, Kaplan e Norton (1997) afirmam que o BSC é um sistema que, 
de modo balanceado, aplica indicadores financeiros e não financeiros, estabelecendo relações de causa e efeito entre estes, possibilitando, a partir daí, construir mapas estratégicos. Reafirmando esta ideia, os autores Kaplan e Norton (2001, p. 81) dizem que "cada indicador do scorecard se converte em parte integrante de uma cadeia ideológica de causa e efeito que conecta os resultados almejados da estratégia com os vetores que induzirão a essas consequências".

De forma a sintetizar todas as ideias, Tavares (2010) argumenta que o BSC constrói uma relação de causa e efeito entre as perspectivas. Começando com o suprimento das necessidades dos colaboradores (conhecimento, informação e sistemas) na perspectiva de aprendizado e crescimento, esta terá uma relação de causa e efeito com perspectiva de processos internos, na medida em que a primeira, se satisfeita, possibilita o desenvolvimento e a inovação de capacidades estratégicas organizacionais, foco da segunda perspectiva.

Após isso, essas perspectivas terão a mesma relação que tiveram entre si (causa e efeito) com a terceira perspectiva (do cliente), criando capacidades de fornecer valor específico aos seus respectivos mercados. Por fim, estas perspectivas terão como efeito um maior desempenho financeiro da empresa, gerando maior lucratividade, maior valor para os acionistas, redução nos custos e aumento no patrimônio empresarial (perspectiva financeira) (TAVARES, 2010).

Em suma, de acordo com Silva (2003), o BSC trabalha com medidas (vetores) tidas como sendo de curto prazo, como as financeiras, unidas às de longo prazo, como os clientes, processos internos e aprendizado e crescimento. Na sequência, apresentar-seão os principais conceitos e descrições de cada uma das quatro perspectivas que compõem o modelo do BSC.

\section{a) Perspectiva financeira}

Os objetivos financeiros da empresa, de acordo com Kaplan e Norton (1997), devem nortear todos os outros objetivos e medidas das demais perspectivas do BSC. Em outras palavras, qualquer medida adotada pela empresa deve integrar uma cadeia de relações de causa e efeito que vislumbram, no final, resultar na melhoria do desempenho financeiro da empresa.
Corroborando com o exposto anteriormente, Hernandes et al. (2000) afirmam que, ao realizar-se a seleção dos indicadores financeiros que serão utilizados no BSC, faz-se necessário ter em mente dois objetivos primordiais: definir o desempenho financeiro esperado por intermédio da estratégia e servir de meta principal para os objetivos e medidas traçadas para todas as outras perspectivas do BSC.

De acordo com Olve, Roy e Wetter (2001) apud Arantes (2006), a perspectiva financeira demonstra o que se espera da organização por parte dos acionistas no que diz respeito a crescimento e lucratividade. Os autores argumentam ainda que essa perspectiva deve expor o que é aceitável em termos de risco, fluxos de caixa negativos e qualquer outra forma de controle financeiro gerencial passível de medição em uma organização.

Em síntese, de acordo com Kaplan e Norton (1997, p. 64), "os objetivos financeiros representam a meta de longo prazo da empresa". Os autores afirmam também que o BSC não conflita com essa meta principal, apenas configura a estratégia da empresa para atrelar e relacionar os outros diversos objetivos propostos aos financeiros, tornando estes mais explícitos para todas as unidades de negócio da empresa.

\section{b) Perspectiva clientes}

De acordo com Kaplan e Norton (1997), a perspectiva dos clientes é responsável por identificar e selecionar os segmentos de mercado onde a empresa dedicará a sua atuação. Esses segmentos se constituirão nas fontes produtoras de receitas mantenedoras da empresa e irão compor os objetivos financeiros da mesma. Em virtude disto, Hernandes et al. (2000) alegam que é relevante estabelecer relações próximas e sinérgicas com os clientes, buscando levantar as percepções que estes possuem sobre a empresa de modo a aperfeiçoar continuamente o atendimento das demandas observadas.

Dessa forma, o grande objetivo desta perspectiva é criar valor superior para os clientes e mercados nos quais se decide atuar, satisfazendo, por fim, as necessidades oriundas do público alvo. Segundo Kaplan e Norton (1997), essa perspectiva possibilita à organização alinhar suas medidas essenciais voltadas aos clientes com segmentos específicos e também aos mercados. 
Estas medidas essenciais são comuns à maioria das empresas, não havendo, porém, um foco específico para um mercado ou um segmento. Devido a isso, Kaplan e Norton (1997) sugerem que as empresas desenvolvam medidas e estratégias personalizadas que se destinem a atingir grupos específicos de clientes com os quais a empresa objetiva obter lucratividade e possibilidades de crescimento.

Arantes (2006) salienta que em decorrência das mudanças advindas da evolução tecnológica, os fatores que agregam valor para os clientes modificam-se rapidamente, exigindo das empresas monitoramento constante. Por isso, uma identificação eficaz das perspectivas dos clientes auxilia a empresa no direcionamento apropriado dos processos internos e das estratégias de alcance de mercado.

\section{c) Perspectiva processos internos}

A concentração de esforços se dá nesta perspectiva no momento em que a empresa ou unidade de negócio concentra esforços nos processos internos para que as perspectivas anteriormente citadas (clientes e financeira) recebam o suporte necessário para que sejam plenamente atingidas (ARANTES, 2006). Em outras palavras, essa perspectiva tem como propósito identificar os processos críticos buscando a melhoria contínua, a fim de dar suporte aos objetivos definidos nas perspectivas anteriores (SILVA; PORTUGAL; SOUZA, 2014).

Complementarmente, Kaplan e Norton (1997, p. 99) afirmam que no BSC "os objetivos e as medidas da perspectiva dos processos internos derivam das estratégias voltadas para o atendimento dos acionistas e clientes-alvo". Para os autores, os convencionais sistemas de medição de desempenho visam apenas melhorar indicadores de custo, qualidade e tempo dos processos já existentes.

Ainda, segundo Kaplan e Norton (1997), são três processos internos principais que as empresas devem focar para garantir bons retornos a clientes e acionistas: o processo de inovação, através do qual se identificam as necessidades dos clientes e posteriormente desenvolvem-se e criam-se produtos correspondentes a estas necessidades; o processo operacional, onde os produtos desde a encomenda do cliente até a entrega ao mesmo devem obedecer a padrões de eficiência e consistência; e o processo de pós-venda, que inclui todos os serviços de apoio ao cliente, auxiliando a busca pela satisfação do mesmo.

\section{d) Perspectiva aprendizado e crescimento}

Prieto et al. (2006) consideram que as empresas aptas a serem melhores são aquelas que têm capacidade evoluída de aprendizagem. Sendo assim, no entendimento de Kaplan e Norton (1997), essa perspectiva tem como principais objetivos a sustentação e a prestação de infraestrutura que possibilitem o alcance das metas traçadas nas três perspectivas anteriores. De acordo com Silva (2003), as fontes principais desta perspectiva são pessoas (capital humano), sistemas (capital de informação) e procedimentos organizacionais (capital organizacional).

Nos modelos tradicionais, que possuem medidas de desempenho baseadas apenas em resultados financeiros, os investimentos em aumento da capacidade de seu pessoal, sistemas e processos organizacionais são tratados meramente como despesas, sendo sua redução uma forma de alavancar os ganhos empresariais (KAPLAN; NORTON, 1997).

Em virtude disto, de acordo com Kaplan e Norton (1997), nesta perspectiva deve ser utilizado um grupo de três indicadores focados nos colaboradores como forma de monitorar os resultados a partir de investimentos feitos em funcionários, sistemas e procedimentos organizacionais. Estes indicadores são a satisfação, produtividade e retenção de colaboradores.

\subsection{Indicadores de desempenho}

De acordo com Padoveze (2012), o indicador de desempenho é um número que colabora com um processo, de forma a clarificá-lo e quantificá-lo, proporcionando um melhor entendimento da situação vivenciada por uma empresa de acordo com diversos aspectos. Ainda, os indicadores de desempenho possuem finalidades como no caso a identificação de tendências institucionais e a prestação de suporte aos gestores no que tange à geração de informações que venham a auxiliar a tomada de decisões apropriadas e no direcionamento de esforços organizacionais para a direção correta.

Descritos como parâmetros por Tavares (2010), estes indicadores permitem medir e julgar o andamento de diversos processos, tidos pelo autor como objetivos e metas. Podem ser classificados como 
parâmetros físicos, como aumento da participação de mercado, novos produtos e novos serviços; monetários, como custo com produção e com departamento pessoal e temporais, como datas limite e duração.

Neste contexto, têm-se como uma das principais utilidades dos indicadores a reflexão de tudo o que foi proposto no planejamento estratégico. A partir de ferramentas como o BSC, os indicadores podem ser organizados em níveis hierárquicos, ligando os diversos setores da empresa, além de tornar os objetivos e as metas da empresa mensuráveis, o que atribui um caráter diferenciado ao plano (MÜLLER, 2003).

Para a Fundação Nacional da Qualidade (2012), um eficiente sistema de indicadores tem, além de constatar que as metas estão sendo alcançadas, uma função igualmente importante: clarear e conectar as diferentes ações entre setores de uma empresa, criando a partir daí um alinhamento e uma linguagem comuns em todos os níveis organizacionais. Além disso, materializar resultados por meio de medidas de desempenho que se façam visíveis aos colaboradores da empresa provoca, internamente, um processo motivacional coletivo na busca pelo sucesso da empresa.

\section{Metodologia}

O método utilizado no presente trabalho consiste em um estudo de caso exploratório-descritivo que, segundo Oliveira (2011), procura analisar um contexto social de forma geral e ampla, permitindo ao pesquisador compreender melhor o comportamento de diversos fatores e elementos que afetam determinado fenômeno. Essa pesquisa caracteriza-se ainda como pesquisa participante, adotada para a coleta de informações aplicadas na análise organizacional.

Pearsall (1968) explica que esse tipo de pesquisa, além de ser uma maneira de obter informações detalhadas junto a informantes, é também um aglomerado de comportamentos dos quais fazem parte o observador. Seu foco principal é obter dados acerca do fenômeno em estudo, através de envolvimento direto. Portanto, a pesquisa participante envolve pesquisador e pesquisado, na qual ambos, juntos, identificam problemas, discutem, buscam soluções e agem, medindo ao final do processo os resultados obtidos.

Como plano de coleta de informações, utilizaram-se dados secundários que, segundo Prodanov e Freitas (2013), referem-se aos dados já disponíveis sobre o assunto, seja em jornais, periódicos, livros etc. Ademais, também fez-se uso de dados primários, obtidos a partir de documentos internos e entrevistas semiestruturadas com os gestores e diretor da empresa. Na Figura 1 é possível visualizar a estrutura adotada na pesquisa.

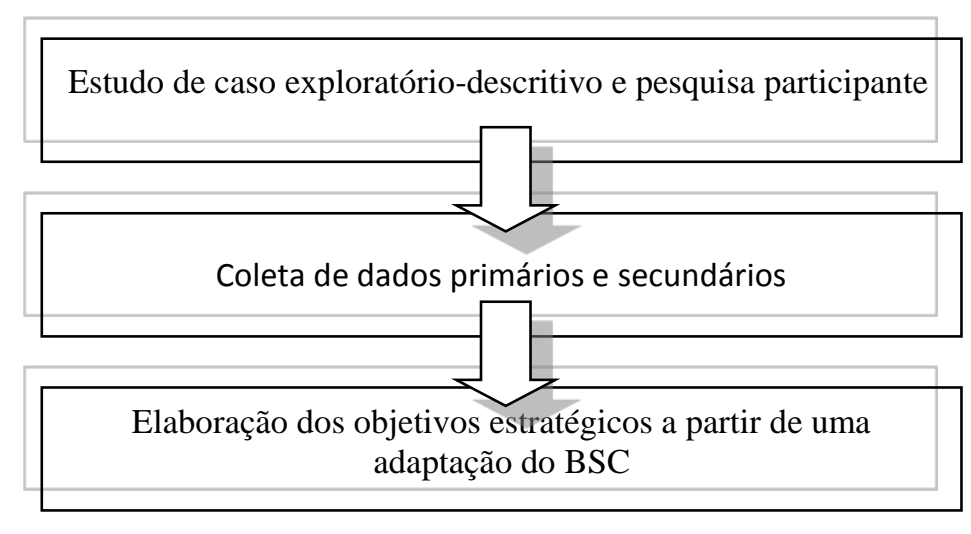

Fonte: Elaborados pelos autores

Cabe frisar que com os dados primários e secundários apontados na Figura 1 foi possível elaborar os objetivos a serem alcançados com o planejamento estratégico a partir de uma adaptação baseada no modelo do BSC na Alpha Insumos Agrícolas (nome fictício adotado, visando preservar a identidade da empresa analisada nesse trabalho). 


\section{Análise dos resultados}

Esse trabalho foi realizado em uma organização de insumos agrícolas, fundada no ano de 1995, localizada na região central do Estado do Rio Grande do Sul, que atua na área de comercialização de commodities agrícolas, tais como: soja, milho, aveia, trigo e arroz, sendo a soja a cultura responsável por $95 \%$ dos negócios da companhia. Além da matriz, a organização conta com mais três filiais. Contudo, essa pesquisa foi realizada apenas na matriz.

Deste modo, obedecendo ao modelo do BSC, os objetivos estratégicos para a Alpha Insumos Agrícolas foram definidos conforme suas perspectivas (financeira, clientes, processos internos e aprendizado e crescimento). Tais objetivos são expostos no Quadro 1.

\section{Quadro 1 - Objetivos estratégicos}

\begin{tabular}{|l|l|}
\hline \multicolumn{1}{|c}{ Perspectiva } & \multicolumn{1}{c}{ Objetivos } \\
\hline Financeira & F1 - Aumentar o faturamento \\
& F2 - Aumentar a lucratividade \\
& C1 - Captação de novos clientes \\
\hline C2 - Satisfação dos clientes & C3 - Fidelidade de clientes \\
\hline Clientes & P1 - Melhorar a utilização dos sistemas de informação \\
\hline P2 - Melhora da comunicação interna \\
\hline Processos Internos & P3 - Padronização e aperfeiçoamento de processos \\
& A1 - Treinamento de funcionários \\
\hline A2 - Reduzir a rotatividade & A3 - Melhorar a perspectiva do funcionário \\
\hline
\end{tabular}

Fonte: Elaborado pelos autores com base nos dados da pesquisa

Destaca-se que os objetivos estratégicos para cada perspectiva, elencados no Quadro 1, foram definidos juntamente com os gestores e diretor da organização a partir de entrevistas semiestruturadas com os mesmos. Todavia, El-Kouba et al. (2009) lembram que o alcance desses objetivos só será possível se os colaboradores acoplarem de forma coletiva o seu comportamento às condições que beneficiam a organização.

\subsection{Planos de ação}

Para cada objetivo estratégico apresentado no Quadro 1 foram definidos planos de ação. Esses planos visam o cumprimento e o alcance dos objetivos e das metas traçados dentro das quatro perspectivas do BSC. Villa et al. (2013) esclarecem que o plano de ação consiste em uma ferramenta que proporciona tanto a elaboração dos planos, como também o seu gerenciamento e padronização. Sendo assim, no Quadro 2 apresentam-se os planos de ação da perspectiva de aprendizado e crescimento. 
Quadro 2 - Planos de ação da perspectiva aprendizado e crescimento

\begin{tabular}{|c|c|c|c|c|c|}
\hline \multicolumn{6}{|c|}{ PLANOS DE AÇÃO - PERSPECTIVA APRENDIZADO E CRESCIMENTO } \\
\hline Objetivo & \multicolumn{5}{|c|}{ Treinamento de funcionários } \\
\hline O QUÊ? & POR QUÊ? & ONDE? & QUEM? & QUANDO? & COMO? \\
\hline $\begin{array}{l}\text { Calendário padrão } \\
\text { de treinamento }\end{array}$ & $\begin{array}{l}\text { Melhorar o desempe- } \\
\text { nho de cada um den- } \\
\text { tro de suas funções. }\end{array}$ & $\begin{array}{l}\text { Em todas as } \\
\text { unidades da or- } \\
\text { ganização. }\end{array}$ & $\begin{array}{c}\text { Departamento de } \\
\text { Recursos Humanos. }\end{array}$ & $\begin{array}{l}\text { Nos meses de } \\
\text { novembro até } \\
\text { janeiro. }\end{array}$ & $\begin{array}{l}\text { Criar programas e } \\
\text { períodos determina- } \\
\text { dos de treinamento }\end{array}$ \\
\hline $\begin{array}{l}\text { Contratações para } \\
\text { cargos específicos } \\
\text { deverão exigir } \\
\text { treinamento }\end{array}$ & $\begin{array}{l}\text { Para que o cargo seja } \\
\text { ocupado por um indi- } \\
\text { víduo capacitado a } \\
\text { cumprir e a crescer } \\
\text { em sua função. }\end{array}$ & $\begin{array}{l}\text { Em todas as } \\
\text { unidades da or- } \\
\text { ganização. }\end{array}$ & $\begin{array}{c}\text { Departamento de } \\
\text { Recursos Humanos. }\end{array}$ & $\begin{array}{l}\text { Durante todo o } \\
\text { ano. }\end{array}$ & $\begin{array}{l}\text { Funcionário somente } \\
\text { começará a trabalhar } \\
\text { após estar apto. }\end{array}$ \\
\hline Objetivo & \multicolumn{5}{|c|}{ Reduzir a rotatividade } \\
\hline O QUÊ? & POR QUÊ? & ONDE? & QUEM? & QUANDO? & COMO? \\
\hline $\begin{array}{l}\text { Identificar causas } \\
\text { da rotatividade }\end{array}$ & $\begin{array}{l}\text { Diminuir a troca de } \\
\text { funcionários implica } \\
\text { em menores custos } \\
\text { com novos treinamen- } \\
\text { tos, bem como man- } \\
\text { tém um padrão de } \\
\text { qualidade alto. }\end{array}$ & $\begin{array}{l}\text { Em todas as } \\
\text { unidades da or- } \\
\text { ganização. }\end{array}$ & $\begin{array}{l}\text { Departamento de } \\
\text { Recursos Humanos } \\
\text { e Gerente Adminis- } \\
\text { trativo. }\end{array}$ & $\begin{array}{l}\text { Durante todo o } \\
\text { ano. }\end{array}$ & $\begin{array}{l}\text { Aplicar uma pesquisa } \\
\text { de clima organizacio- } \\
\text { nal, visando identifi- } \\
\text { car as possíveis cau- } \\
\text { sas da rotatividade. }\end{array}$ \\
\hline Objetivo & \multicolumn{5}{|c|}{ Melhorar a perspectiva do funcionário } \\
\hline O QUÊ? & POR QUÊ? & ONDE? & QUEM? & QUANDO? & COMO? \\
\hline $\begin{array}{l}\text { Plano de cargos e } \\
\text { salários }\end{array}$ & $\begin{array}{l}\text { Dar ao funcionário a } \\
\text { possibilidade de cres- } \\
\text { cimento dentro da } \\
\text { organização, dimi- } \\
\text { nuindo assim a rotati- } \\
\text { vidade. }\end{array}$ & $\begin{array}{l}\text { Primeiramente } \\
\text { aplicado na Ma- } \\
\text { triz da organiza- } \\
\text { ção. }\end{array}$ & $\begin{array}{l}\text { Departamento de } \\
\text { Recursos Humanos } \\
\text { e diretoria. }\end{array}$ & $\begin{array}{l}\text { Durante o ano } \\
\text { todo. }\end{array}$ & $\begin{array}{c}\text { Planejar e apresentar } \\
\text { para os funcionários, } \\
\text { no momento da ad- } \\
\text { missão as suas possi- } \\
\text { bilidades de cresci- } \\
\text { mento na organiza- } \\
\text { ção. }\end{array}$ \\
\hline $\begin{array}{l}\text { Aumentar a satis- } \\
\text { fação do funcio- } \\
\text { nário }\end{array}$ & $\begin{array}{l}\text { A satisfação no traba- } \\
\text { lho é inversamente } \\
\text { proporcional à rotati- } \\
\text { vidade. }\end{array}$ & $\begin{array}{l}\text { Em todas as } \\
\text { unidades da or- } \\
\text { ganização. }\end{array}$ & $\begin{array}{l}\text { Departamento de } \\
\text { Recursos humanos. }\end{array}$ & $\begin{array}{l}\text { Durante o ano } \\
\text { todo. }\end{array}$ & $\begin{array}{l}\text { Promover uma festa } \\
\text { de integração por } \\
\text { trimestre, bem como } \\
\text { melhorar as estruturas } \\
\text { de vestiário e refeitó- } \\
\text { rio. }\end{array}$ \\
\hline
\end{tabular}

Fonte: Elaborado pelos autores com base nos dados da pesquisa

No Quadro 2 foram apresentados os planos que buscam, dentro da perspectiva de aprendizado e crescimento, a melhora do desempenho dos funcionários em suas funções a partir do investimento em treinamento para os mesmos, bem como o aumento da satisfação dos colaboradores e a consequente diminuição da rotatividade.

Acerca do treinamento, é importante destacar o apontamento realizado por Volpe e Lorusso (2009) que, levando em conta a instabilidade e competitividade do mercado, as empresas precisam estar preparadas para esses desafios, e para ter sucesso na prática os colaboradores precisam estar preparados, por isso o treinamento e desenvolvimento são fundamentais. O Quadro 3 apresenta os planos da perspectiva dos processos internos.

Quadro 3 - Planos de ação da perspectiva processos internos

\begin{tabular}{|c|c|c|c|c|}
\hline & \multicolumn{4}{|c|}{ PLANOS DE AÇÃO - PERSPECTIVA DOS PROCESSOS INTERNOS } \\
\hline Objetivo & \multicolumn{3}{|c|}{ Melhorar a utilização dos sistemas de informação } \\
\hline O QUÊ? & POR QUÊ? & ONDE? & QUEM? & QUANDO? \\
\hline
\end{tabular}


Aumentar o desempenho na utilização dos sistemas de informação
Todos os sistemas dentro da organização são pouco explorados, ou seja, não são utilizados ao máximo todos os recursos.
Em todas as unidades da organização.
Fornecedores dos sistemas e técnico de Tecnologia da Informação (TI).
Período entre os meses de agosto e fevereiro.
Através de treinamento dos funcionários mediante visita das organização fornecedoras dos softwares e $e$ learning (treinamento virtual).

Faz-se necessário a padronização e regula-

Prevenção de erros mentação dos principais procedimentos dos sistemas informacionais, como forma de suporte em caso de dúvidas. no trabalho
Em todas as unidades da organização.
Responsáveis por cada sistema presente na organização.
Período entre

os meses de outubro a janeiro.
Construção de um manual envolvendo os sistemas de informação

\section{Objetivo} O QUÊ?

\section{Padronizar canais} de comunicação internos

\section{Melhorar a comunicação interna}

POR QUÊ?

Há falhas que provocam diversos problemas no andamento das atividades, gerando, por vezes, custos excessivos e insatisfação de clientes.

\section{ONDE?} QUEM?
Em todas as unidades da organização.

\section{Área administrativa \\ Período entre} da organização e fornecedora de softwares da Alpha.

\section{QUANDO?} os meses de junho e setembro.

\section{COMO?}

Aquisição de um comunicador padrão, junto à organização gerenciadora

das redes internas da organização.

Formalização de um calendário, bem

Não existe na rotina da organização reuniões formais, o que dificulta o fluxo de informações do topo até sua base.

\begin{tabular}{|c|}
\hline $\begin{array}{l}\text { Em todas as } \\
\text { unidades da } \\
\text { organizacão }\end{array}$ \\
\hline
\end{tabular}

como de uma ata que será formalizada e assinada ao final de cada sessão.

\section{Padronização e aperfeiçoamento de processos}

\section{O QUÊ?}

POR QUÊ?

Percebe-se que um processo muitas vezes é realizado de maneira

Mapear os principais processos da organização

distinta por não haver padronização. Esta falha acarreta em insatisfação de funcionários, bem como pro-

blemas na comunicação interna.

Não há um controle claro e seguro quanto ao departamento finan-

Melhoria do controle financeiro da organização

Melhora do controle da logística organizacional ceiro. O controle é feito com planilhas do software Excel $^{\circledR}$, sem o uso do sistema principal.

A logística, maior custo fixo dos produtos da organização, não possui um sistema gerencial. É controlada em planilhas do software $\mathrm{Excel}^{\circledR}$.

\section{ONDE?}

QUEM?

\section{QUANDO?}

\section{COMO?}

Designar alguém qualificado para mapear os principais
Primeiramente aplicado na matriz da organização.
Área administrativa da organização.
Durante todo o ano. processos da organização e treinar os funcionários para um melhor entendimento da ferramenta utilizada.

Utilização de relatórios do sistemas,

\section{Na matriz da} organização.

\section{Área administrativa} e diretoria.
A partir do mês de junho. bem como a retirada do controle diário por parte do diretor da organização.

Controle de fretes via sistema principal da organização.
Matriz da organização.
Diretoria e área comercial.
Até fevereiro de 2015 .
Eliminação de planilhas do software Excel®.

Fonte: Elaborado pelos autores com base nos dados da pesquisa 
Analisando o Quadro 3, nota-se a preocupação da organização com a padronização dos processos, melhora da comunicação interna e aumento do controle em setores como finanças e logística, tudo isso corroborando a preocupação de melhorar os serviços prestados na busca por uma satisfação cada vez maior dos clientes. Vale frisar que clientes satisfei- tos e fieis tem como tendência comprar mais, inclusive aceitam pagar mais caro pelo produto ofertado além de tecer comentários positivos sobre a empresa (FELIXAN; SILVA; MAGALHÃES, 2012). Na sequência, visualizam-se no Quadro 4 os planos de ação da perspectiva dos clientes.

\section{Quadro 4 - Planos de ação da perspectiva clientes}

\begin{tabular}{|c|c|c|c|c|c|}
\hline \multicolumn{6}{|c|}{ PLANOS DE AÇÃO - PERSPECTIVA DOS CLIENTES } \\
\hline Objetivo & \multicolumn{5}{|c|}{ Captação de novos clientes } \\
\hline O QUÊ? & POR QUÊ? & ONDE? & QUEM? & QUANDO? & COMO? \\
\hline $\begin{array}{l}\text { Aumentar car- } \\
\text { teira de clientes } \\
\text { da organização }\end{array}$ & $\begin{array}{c}\text { Aumentar o faturamento } \\
\text { da organização. }\end{array}$ & $\begin{array}{l}\text { Na matriz da } \\
\text { organização. }\end{array}$ & Área comercial. & $\begin{array}{l}\text { Durante todo o } \\
\text { ano. }\end{array}$ & $\begin{array}{l}\text { Por meio de programas } \\
\text { de marketing voltados } \\
\text { para a captação de novos } \\
\text { clientes. Não só os de- } \\
\text { positantes, mas buscar a } \\
\text { compra de soja disponí- } \\
\text { vel em armazéns dos } \\
\text { próprios clientes. }\end{array}$ \\
\hline $\begin{array}{l}\text { Novos produtos } \\
\text { e serviços }\end{array}$ & $\begin{array}{l}\text { Com novos produtos, } \\
\text { abrem-se novos mercados, } \\
\text { captam-se novos clientes e, } \\
\text { consequentemente, aumen- } \\
\text { ta-se o faturamento. }\end{array}$ & $\begin{array}{l}\text { Em todas as } \\
\text { unidades da } \\
\text { organização. }\end{array}$ & Área comercial. & $\begin{array}{l}\text { Durante o ano } \\
\text { todo. }\end{array}$ & $\begin{array}{l}\text { Aumento dos investi- } \\
\text { mentos no setor de grãos } \\
\text { semente, com incremen- } \\
\text { to de novas tecnologias } \\
\text { e variedades. }\end{array}$ \\
\hline Objetivo & \multicolumn{5}{|c|}{ Satisfação dos clientes } \\
\hline O QUÊ? & POR QUÊ? & ONDE? & QUEM? & QUANDO? & COMO? \\
\hline $\begin{array}{l}\text { Aumentar a } \\
\text { percepção de } \\
\text { valor dos clien- } \\
\text { tes. }\end{array}$ & $\begin{array}{c}\text { Atender a demanda dos } \\
\text { clientes, com vista a tornar } \\
\text { o serviço da empresa reco- } \\
\text { nhecido no mercado. }\end{array}$ & $\begin{array}{l}\text { Em todas as } \\
\text { unidades da } \\
\text { organização. }\end{array}$ & $\begin{array}{l}\text { Toda a organi- } \\
\text { zação. }\end{array}$ & $\begin{array}{l}\text { Durante todo o } \\
\text { ano. }\end{array}$ & $\begin{array}{l}\text { Aumentar a velocidade } \\
\text { de recebimento e expe- } \\
\text { dição de cargas, buscar } \\
\text { sempre os melhores } \\
\text { preços no mercado e dar } \\
\text { segurança aos clientes. }\end{array}$ \\
\hline $\begin{array}{l}\text { Redesenhar o } \\
\text { layout do escri- } \\
\text { tório da matriz }\end{array}$ & $\begin{array}{l}\text { Não há um estrutura corre- } \\
\text { ta para atendimento dos } \\
\text { clientes. O tempo de espe- } \\
\text { ra dos mesmos está acima } \\
\text { do apropriado, fator esse } \\
\text { que causa aglomeração em } \\
\text { locais indesejados. }\end{array}$ & $\begin{array}{l}\text { Na matriz da } \\
\text { organização. }\end{array}$ & $\begin{array}{l}\text { Gerentes e dire- } \\
\text { tor. }\end{array}$ & $\begin{array}{l}\text { Período entre os } \\
\text { meses de junho } \\
\text { e dezembro. }\end{array}$ & $\begin{array}{l}\text { Com o mapeamento do } \\
\text { principal processo da } \\
\text { organização, o layout } \\
\text { será pensado com vista a } \\
\text { corresponder ao máximo } \\
\text { o fluxo designado. }\end{array}$ \\
\hline Objetivo & \multicolumn{5}{|c|}{ Fidelidade de clientes } \\
\hline O QUÊ? & POR QUÊ? & ONDE? & QUEM? & QUANDO? & COMO? \\
\hline $\begin{array}{l}\text { Reter os atuais } \\
\text { clientes da or- } \\
\text { ganização }\end{array}$ & $\begin{array}{l}\text { Para expansão da carteira } \\
\text { de clientes é necessário, } \\
\text { primeiramente, manter os } \\
\text { atuais. É muito mais one- } \\
\text { roso conquistar o cliente } \\
\text { novamente do que mantê- } \\
\text { lo na organização. }\end{array}$ & $\begin{array}{l}\text { Em todas as } \\
\text { unidades da } \\
\text { organização. }\end{array}$ & $\begin{array}{l}\text { Área comercial da } \\
\text { organização. }\end{array}$ & $\begin{array}{l}\text { Durante o ano } \\
\text { todo. }\end{array}$ & $\begin{array}{l}\text { Realização de eventos } \\
\text { em datas comemora- } \\
\text { tivas, distribuição de } \\
\text { brindes aos principais } \\
\text { clientes e canais de } \\
\text { comunicação direta } \\
\text { com o produtor. }\end{array}$ \\
\hline $\begin{array}{l}\text { Oferecer novos } \\
\text { planos de com- } \\
\text { pras aos clientes }\end{array}$ & $\begin{array}{l}\text { Os concorrentes estão cada } \\
\text { vez mais desenvolvendo } \\
\text { pacotes de vendas, que } \\
\text { agrupam defensivos, ferti- } \\
\text { lizantes e grãos. }\end{array}$ & $\begin{array}{l}\text { Na matriz da } \\
\text { organização. }\end{array}$ & Área comercial & $\begin{array}{l}\text { Durante todo o } \\
\text { ano. }\end{array}$ & $\begin{array}{l}\text { Desenvolver novos } \\
\text { planos e novos tipos } \\
\text { de negociação com o } \\
\text { produtor, com vista a } \\
\text { mantê-los dentro do } \\
\text { grupo organizacional. }\end{array}$ \\
\hline
\end{tabular}

Fonte: Elaborado pelos autores com base nos dados da pesquisa 
Os planos mencionados no Quadro 4, da perspectiva dos clientes, mostram o objetivo que a organização tem de aumentar o seu número de clientes, assim como reter e intensificar os depósitos dos atuais. Para isso, investir no desenvolvimento de novos produtos, além de melhorar os já existentes é fundamental e, é nesse sentido que foram traçados os planos de ação apresentados. Almeida, Miguel e Carvalho (2011) reforçam esse posicionamento ela- borado, pois julgam que essa necessidade de desenvolver novos produtos precisa despontar dos planos estratégicos da organização.

É importante ressaltar que o BSC, além de proporcionar a organização esse tipo de planejamento de ações também pode auxiliar na resolução de vários problemas (FERREIRA; DIEH, 2013). Em continuidade, observam-se no Quadro 5 os planos de ação referentes à perspectiva financeira.

Quadro 5 - Planos de ação da perspectiva financeira

\begin{tabular}{|c|c|c|c|c|c|}
\hline \multicolumn{6}{|c|}{ PLANOS DE AÇÃO - PERSPECTIVA FINANCEIRA } \\
\hline Objetivo & \multicolumn{5}{|c|}{ Aumentar o faturamento } \\
\hline O QUÊ? & POR QUÊ? & ONDE? & QUEM? & QUANDO? & COMO? \\
\hline $\begin{array}{l}\text { Aumentar o volume } \\
\text { de depósitos. }\end{array}$ & $\begin{array}{l}\text { Aumentar o fatu- } \\
\text { ramento proporcio- } \\
\text { na à organização } \\
\text { maior investimento } \\
\text { e melhorias na sua } \\
\text { infraestrutura. }\end{array}$ & $\begin{array}{l}\text { Na matriz da } \\
\text { organização. }\end{array}$ & $\begin{array}{l}\text { Área co- } \\
\text { mercial. }\end{array}$ & $\begin{array}{l}\text { Durante todo } \\
\text { o ano. }\end{array}$ & $\begin{array}{l}\text { A partir do aumento da carteira de } \\
\text { clientes, bem como da expansão para } \\
\text { novas regiões. Ainda, convencer os } \\
\text { atuais clientes a depositarem uma } \\
\text { maior \% de sua safra. }\end{array}$ \\
\hline Objetivo & \multicolumn{5}{|c|}{ Aumentar a lucratividade } \\
\hline O QUÊ? & POR QUÊ? & ONDE? & QUEM? & QUANDO? & COMO? \\
\hline Novas unidades & $\begin{array}{l}\text { Novas unidades, } \\
\text { em regiões de pou- } \\
\text { ca atuação da orga- } \\
\text { nização aumentam } \\
\text { a participação da } \\
\text { organização no } \\
\text { mercado. }\end{array}$ & $\begin{array}{c}\text { Matriz da } \\
\text { organização. }\end{array}$ & $\begin{array}{l}\text { Diretoria e } \\
\text { área co- } \\
\text { mercial. }\end{array}$ & $\begin{array}{l}\text { Durante todo } \\
\text { o ano. }\end{array}$ & $\begin{array}{l}\text { Através do investimento em novas } \\
\text { estruturas de recebimento em regiões } \\
\text { onde a organização possui pequenas } \\
\text { fatias de mercado. }\end{array}$ \\
\hline $\begin{array}{l}\text { Corte de despesas } \\
\text { desnecessárias }\end{array}$ & $\begin{array}{l}\text { Melhorar o retorno } \\
\text { para os acionistas, } \\
\text { bem como incorpo- } \\
\text { rar dentro da orga- } \\
\text { nização uma cultu- } \\
\text { ra de corte de des- } \\
\text { pesas desnecessá- } \\
\text { rias e busca por } \\
\text { negócios mais } \\
\text { rentáveis. }\end{array}$ & $\begin{array}{l}\text { Em todas as } \\
\text { unidades da } \\
\text { organização. }\end{array}$ & $\begin{array}{l}\text { Diretoria e } \\
\text { gerentes de } \\
\text { área. }\end{array}$ & $\begin{array}{l}\text { Durante o } \\
\text { ano todo. }\end{array}$ & $\begin{array}{c}\text { Eliminar processos inúteis e repetiti- } \\
\text { vos dentro da organização. }\end{array}$ \\
\hline $\begin{array}{l}\text { Investir em negócios } \\
\text { de maior margem de } \\
\text { lucro }\end{array}$ & $\begin{array}{l}\text { Uma margem mai- } \\
\text { or possibilita cres- } \\
\text { cimento na taxa de } \\
\text { lucratividade. }\end{array}$ & $\begin{array}{l}\text { Na matriz da } \\
\text { organização. }\end{array}$ & Diretoria. & $\begin{array}{l}\text { Durante todo } \\
\text { o ano. }\end{array}$ & $\begin{array}{c}\text { Investimento em áreas de maior retor- } \\
\text { no da organização, como sementes e } \\
\text { defensivos agrícolas. }\end{array}$ \\
\hline $\begin{array}{l}\text { Melhorar o planeja- } \\
\text { mento logístico }\end{array}$ & $\begin{array}{l}\text { Sendo o transporte } \\
\text { o principal custo } \\
\text { por saca de produto } \\
\text { da organização, é } \\
\text { necessário que haja } \\
\text { um controle e um } \\
\text { desempenho cada } \\
\text { vez melhor na área. }\end{array}$ & $\begin{array}{l}\text { Na matriz da } \\
\text { organização. }\end{array}$ & $\begin{array}{l}\text { Área co- } \\
\text { mercial. }\end{array}$ & $\begin{array}{l}\text { Durante o } \\
\text { ano todo. }\end{array}$ & $\begin{array}{l}\text { Maior integração da cadeia de supri- } \\
\text { mentos (SCM). }\end{array}$ \\
\hline
\end{tabular}

Fonte: Elaborado pelos autores com base nos dados da pesquisa 
Pela análise no Quadro 5 verifica-se que, em termos gerais, os planos de ação da perspectiva financeira mostram a preocupação da organização em aumentar o seu faturamento através do crescimento do volume recebido e negociado, como também de melhorar a sua margem de lucro através de diminuição de custos gerais ou a partir do investimento em negócios que tenham um retorno maior do que os atuais.

Considerando que essa perspectiva no BSC necessita ter como foco o gerenciamento dos riscos financeiros (Soares; Simões Junior; Tinoco, 2010), as metas precisam ser definidas em conformidade com o interesse monetário dos gestores da organização (RAMIRES, 2010). Por isso, tais ações foram estabelecidas junto com os gestores e diretor da empresa. A seguir, são apresentados os indicadores de desempenho da organização, que buscam proporcionar à mesma o acompanhamento de algumas atividades e avaliar o seu desempenho em relação às demais.

\subsection{Indicadores de desempenho}

Este item apresenta os indicadores delineados para a Alpha Insumos Agrícolas, visando medir o desempenho da organização em razão de algumas variáveis. O principal motivo para a utilização desses indicadores é avaliar e acompanhar o desenvolvimento das atividades da organização na busca pelos objetivos estratégicos traçados. Deste modo, no Quadro 6 são exibidos os indicadores relacionados à perspectiva aprendizado e crescimento.

\section{Quadro 6 - Indicadores da perspectiva aprendizado e crescimento}

\begin{tabular}{|c|c|c|}
\hline \multicolumn{3}{|c|}{ INDICADORES - PERSPECTIVA APRENDIZADO E CRESCIMENTO } \\
\hline Objetivo & \multicolumn{2}{|c|}{ Treinamento de funcionários } \\
\hline INDICADOR & MENSURAÇÃO & PERIODICIDADE \\
\hline $\begin{array}{l}\text { Porcentagem do faturamento } \\
\text { investido em treinamento }\end{array}$ & $\frac{\text { Despesas com treinamento }}{\text { Receita bruta }}$ & Trimestral \\
\hline $\mathrm{N}^{\mathrm{o}}$. de horas de treinamento & Soma das horas totais de treinamento & Anual \\
\hline Objetivo & \multicolumn{2}{|l|}{ Reduzir rotatividade } \\
\hline INDICADOR & MENSURAÇÃO & PERIODICIDADE \\
\hline Índice de rotatividade & $\frac{n^{0} \text { de admissões }+n^{0} \text { demissões } / 2}{n^{0} \text { total de funcionários }}$ & Anual \\
\hline $\begin{array}{l}\text { Taxa de satisfação do funcioná- } \\
\text { rio }\end{array}$ & Obtida através de uma pesquisa de clima organizacional & Anual \\
\hline Índice de absenteísmo & $\frac{\text { Horas perdidas }}{\text { Horas trabalhadas }}$ & Semestral \\
\hline Objetivo & \multicolumn{2}{|c|}{ Melhorar a perspectiva do funcionário } \\
\hline INDICADOR & MENSURAÇÃO & PERIODICIDADE \\
\hline $\begin{array}{l}\text { Melhora da remuneração total } \\
\text { dos funcionários }\end{array}$ & $\frac{\text { Soma salários base do período }}{\text { Soma salários base do período anterior }}$ & Semestral \\
\hline $\begin{array}{l}\text { Número de promoções (cargos } \\
\text { mais elevados) }\end{array}$ & $\begin{array}{l}\text { Obtido através da soma da quantidade de promoções } \\
\text { ocorridas no período. }\end{array}$ & Semestral \\
\hline $\begin{array}{l}\text { Expectativa do funcionário } \\
\text { sobre seu futuro na organização }\end{array}$ & Obtida através de uma pesquisa de clima organizacional & Anual \\
\hline
\end{tabular}

Fonte: Elaborado pelos autores com base nos dados da pesquisa

Os indicadores da perspectiva aprendizado e crescimento mostrados no Quadro 6 procuram, em termos gerais, medir a evolução da gestão empresarial quanto ao investimento em treinamento, bem como a evolução e satisfação do funcionário dentro da organização. E isso é muito importante mensurar porque é nessa perspectiva que começam as ativi- dades necessárias para que se possa cumprir o planejamento estratégico - o desenvolvimento do capital humano é uma das fontes de vantagem competitiva (CASTRO et al., 2015). Em seguida, constam no Quadro 7 os indicadores da perspectiva dos processos internos. 
Quadro 7 - Indicadores da perspectiva processos internos

\begin{tabular}{|c|c|c|}
\hline \multicolumn{3}{|c|}{ INDICADORES - PERSPECTIVA DOS PROCESSOS INTERNOS } \\
\hline Objetivo & Melhorar a utilização dos sistemas de info & nação \\
\hline INDICADOR & MENSURAÇÃO & PERIODICIDADE \\
\hline $\begin{array}{l}\text { Valor investido em treinamento } \\
\text { específico para TI }\end{array}$ & $\begin{array}{l}\text { Obtida pela soma dos valores investidos em treinamento } \\
\text { dos sistemas utilizados internamente na organização. }\end{array}$ & Anual \\
\hline Taxa de autonomia no trabalho & Obtida por meio de uma pesquisa de clima organizacional. & Anual \\
\hline Objetivo & \multicolumn{2}{|l|}{ Melhora da comunicação interna } \\
\hline INDICADOR & MENSURAÇÃO & PERIODICIDADE \\
\hline $\begin{array}{l}\text { Taxa de satisfação dos atuais canais } \\
\text { de comunicação }\end{array}$ & Obtida através de uma pesquisa de clima organizacional. & Anual \\
\hline $\begin{array}{l}\text { Índice de investimento em canais de } \\
\text { comunicação }\end{array}$ & $\begin{array}{l}\text { Obtida pela divisão dos investimentos em canais de comu- } \\
\text { nicação pelo total das receitas. }\end{array}$ & Anual \\
\hline Objetivo & \multicolumn{2}{|l|}{ Melhora da comunicação interna } \\
\hline INDICADOR & MENSURAÇÃO & PERIODICIDADE \\
\hline Número de reuniões realizadas & $\begin{array}{l}\text { Obtida pelo somatório das reuniões presentes nas atas } \\
\text { durante o período. }\end{array}$ & Semestral \\
\hline Objetivo & \multicolumn{2}{|c|}{ Padronização e aperfeiçoamento de processos } \\
\hline INDICADOR & MENSURAÇÃO & PERIODICIDADE \\
\hline $\begin{array}{l}\text { Porcentagem dos processos mapea- } \\
\text { dos }\end{array}$ & $\frac{\text { Processos mapeados no período }}{\text { Processos mapeados no período anterior }}$ & Anual \\
\hline Taxa de retrabalho (sistema fiscal) & $\frac{\text { Número de notas canceladas }}{\text { Número total de notas emitidas }}$ & Mensal \\
\hline $\begin{array}{l}\text { Índice de informações imprecisas nos } \\
\text { relatórios financeiros e logísticos }\end{array}$ & $\begin{array}{l}\text { Obtida pela divisão do número de relatórios errados pelo } \\
\text { total dos dias analisados. }\end{array}$ & Trimestral \\
\hline
\end{tabular}

Fonte: Elaborado pelos autores com base nos dados da pesquisa

Quadro 8 - Indicadores da perspectiva clientes

\begin{tabular}{|c|c|c|}
\hline \multicolumn{3}{|c|}{ INDICADORES - PERSPECTIVA DOS CLIENTES } \\
\hline Objetivo & Captação de novos clientes & \\
\hline INDICADOR & MENSURAÇÃO & PERIODICIDADE \\
\hline $\begin{array}{l}\text { Taxa de aumento da carteira de } \\
\text { clientes }\end{array}$ & $\frac{n-\text { de clientes que depositaram período }}{n^{0} \text { clientes que depositaram período anterior }}$ & Anual \\
\hline $\begin{array}{l}\text { Índice de investimento em } \\
\text { novos produtos }\end{array}$ & $\begin{array}{l}\text { Obtida pela divisão do total investido em desenvolvimento de estrutura } \\
\text { para novos produtos. }\end{array}$ & Anual \\
\hline $\begin{array}{l}\text { Número de clientes cadastrados } \\
\text { no sistema }\end{array}$ & $\begin{array}{l}\text { Obtida através da observação do aumento do número de clientes cadas- } \\
\text { trados no sistema interno da organização }\end{array}$ & Anual \\
\hline Objetivo & Satisfação dos clientes & \\
\hline INDICADOR & MENSURAÇÃO & PERIODICIDADE \\
\hline Nota de satisfação dos clientes & Obtida através de uma pesquisa de satisfação realizada com os clientes. & Semestral \\
\hline $\begin{array}{l}\text { Taxa de aceitação das sugestões } \\
\text { feitas por clientes }\end{array}$ & $\frac{n^{\circ} \text { de sugestões executadas }}{n^{\circ} \text { de sugestões totais }}$ & Semestral \\
\hline $\begin{array}{l}\text { Nota de aprovação dos clientes } \\
\text { para modificações ocorridas no } \\
\text { layout do escritório }\end{array}$ & Obtida através de uma pesquisa de satisfação realizada com os clientes. & Anual \\
\hline Objetivo & Fidelidade de clientes & \\
\hline INDICADOR & MENSURAÇÃO & PERIODICIDADE \\
\hline Taxa de lealdade dos clientes & $\begin{array}{c}\text { Obtida através da análise da periodicidade de depósitos realizados pelos } \\
\text { clientes. }\end{array}$ & Anual \\
\hline $\begin{array}{l}\text { Taxa de variação do volume } \\
\text { depositado pelos clientes }\end{array}$ & $\frac{\text { Volume depositado pelo cliente " } \mathrm{x} \text { " no ano }}{\text { Volume depositado pelo cliente " } x \text { " ano anterior }}$ & Anual \\
\hline Número de vendas "casadas" & $\begin{array}{c}\text { Obtida através da soma das negociações fechadas em conjunto com as } \\
\text { outras organizações do grupo. }\end{array}$ & A cada dois anos. \\
\hline
\end{tabular}

Fonte: Elaborado pelos autores com base nos dados da pesquisa 
O Quadro 7 exibiu os indicadores da perspectiva dos processos internos, traduzindo a intenção da organização em buscar a melhoria dos serviços em termos de agilidade e qualidade, principalmente sustentada pelo mapeamento dos principais processos da organização. Ademais, há uma preocupação em padronizar e aumentar a eficiência da comunicação interna que atualmente apresenta falhas.

Por isso, recomenda-se que a empresa tenha uma atenção especial no que tange a sua comunicação interna, provendo os ajustes necessários a fim de solucionar as deficiências constatadas. Isso porque a comunicação interna pode afetar tanto positiva como negativamente o desempenho da empresa, inclusive sendo considerada um fator estratégico para o sucesso no mercado, já que depende-se dela para conquistar os melhores resultados (LIMA et al., 2012). No Quadro 8 seguem os indicadores da perspectiva dos clientes.

O Quadro 8, que revela os indicadores da perspectiva dos clientes, proporciona enxergar a visão da empresa, que é de crescimento. Uma organização que pretende expandir sua carteira de clientes e, ao mesmo tempo, aumentar os volumes negociados dos atuais clientes, claramente tem intenção de crescer dentro do mercado. Dessa forma, podem-se destacar os indicadores de aumento da carteira de clientes, a taxa de satisfação dos mesmos e a taxa de variação dos volumes depositados pelos atuais clientes como fundamentais para acompanhar e medir o desempenho da organização na busca pelos objetivos nessa perspectiva.

É válido ressaltar que a construção de um relacionamento instável e sólido com os clientes vai muito além do aumento nas vendas, o próprio valor de mercado da organização sofre influência desse relacionamento representado pela garantia de receitas futuras (FREIRE; DALTO, 2008). Sendo assim, além de expandir a carteira de clientes também manter os atuais tendo um bom relacionamento e buscando satisfazer suas necessidades deve estar entre as estratégias fundamentais de toda e qualquer empresa que planeja prosperar no mercado. A seguir, no Quadro 9 podem-se analisar os indicadores da perspectiva financeira.

Quadro 9 - Indicadores da perspectiva financeira

\begin{tabular}{|c|c|c|}
\hline \multicolumn{3}{|c|}{ INDICADORES - PERSPECTIVA FINANCEIRA } \\
\hline Objetivo & \multicolumn{2}{|l|}{ Aumentar o faturamento } \\
\hline INDICADOR & MENSURAÇÃO & PERIODICIDADE \\
\hline Faturamento & Obtida pelo valor total das vendas e serviços prestados & Anual \\
\hline Receita dos novos produtos & Obtida pela venda de novas variedades de sementes & Anual \\
\hline $\begin{array}{l}\text { Preço médio de compra das } \\
\text { commodities }\end{array}$ & $\begin{array}{l}\text { Obtida pela divisão do total pago aos produtores pelo } \\
\text { volume total de sacas compradas. }\end{array}$ & Anual \\
\hline Preço médio de venda & $\begin{array}{l}\text { Obtida pela divisão do total recebido das traders pelo } \\
\text { volume total de sacas vendidas. }\end{array}$ & Anual \\
\hline $\begin{array}{l}\text { Porcentual de representação de } \\
\text { cada unidade no faturamento } \\
\text { total da organização }\end{array}$ & $\begin{array}{l}\text { Obtida pela divisão do faturamento de cada unidade } \\
\text { pelo total da organização }\end{array}$ & Anual \\
\hline Valor agregado por colaborador & $\begin{array}{l}\text { Obtida pela divisão do lucro líquido pelo total de cola- } \\
\text { boradores na organização }\end{array}$ & Trimestral \\
\hline Objetivo & \multicolumn{2}{|l|}{ Aumentar a lucratividade } \\
\hline INDICADOR & MENSURAÇÃO & PERIODICIDADE \\
\hline Índice de lucratividade & $\frac{\text { Lucro líquido }}{\text { Receitas totais }}$ & Anual \\
\hline Retorno sobre o investimento & $\frac{\text { Lucro líquido }}{\text { Total do ativo operacional }}$ & Anual \\
\hline Margem operacional líquida & $\begin{array}{c}\frac{\text { Lucro operacional }}{\text { Vendas líquidas }} \times 100 \\
\text { (Calcula-se a do período corrente e a do ano anterior } \\
\text { para comparação) }\end{array}$ & Anual \\
\hline Custo por saca vendida & $\frac{\text { Custos totais }}{\text { Volume total de sacos }}$ & Anual \\
\hline
\end{tabular}

Fonte: Elaborado pelos autores com base nos dados da pesquisa 
Percebe-se que, pelo número de indicadores existentes no Quadro 9, será possível obter diversas informações financeiras acerca da organização, o que facilita a mensuração do desempenho dentro dessa perspectiva do BSC. Nesse sentido, Back, Dutra e Casagrande (2012) pontuam que essa necessidade tanto de medir os resultados como avaliar o desempenho das ações estratégicas é uma prática que vem se destacando no cenário atual global.

Deste modo, espera-se que a partir dos indicadores de desempenho elaborados para a Alpha Insumos Agrícolas seja possível avaliar e obter informações importantes a respeito de suas atividades, bem como medir se os planos de ação traçados estão sendo cumpridos. Isso tendo em vista o alcance dos objetivos estratégicos definidos, a fim de melhorar cada vez mais seu desempenho no mercado, a ponto de ser reconhecida pelos seus clientes e colaboradores nas suas relações dentro do agronegócio no Estado do Rio Grande do Sul.

\section{Considerações finais}

Com a realização desse estudo foram elaborados os objetivos estratégicos para a Alpha Insumos Agrícolas a serem alcançados com o planejamento estratégico a partir de uma adaptação baseada no modelo do BSC. Deste modo, a orientação estratégica fundamentada na visão organizacional tornou possível formalizar os objetivos estratégicos, planos de ação e indicadores de desempenho.

Sendo assim, nos planos de ação, na perspectiva de aprendizado e crescimento, foram definidos como objetivos o treinamento de funcionários, a redução da rotatividade e melhoria na perspectiva do funcionário. Enquanto na perspectiva dos processos internos estabeleceu-se melhorar a utilização dos sistemas de informação, como também a comunicação interna e, ainda, a padronização e aperfeiçoamento de processos. Já na perspectiva dos clientes, o propósito será a captação de novos clientes, a satisfação e fidelidade dos mesmos. E, na perspectiva financeira, por sua vez, aumentar o faturamento e a lucratividade foram as metas traçadas.

A respeito dos indicadores de desempenho, em termos gerais, foram elaborados os seguintes objetivos: medir a evolução da gestão empresarial em relação ao treinamento, evolução e satisfação do funcionário (perspectiva aprendizado e crescimento); buscar a melhoria dos serviços em termos de agilidade e qualidade (perspectiva processos internos); aumentar a carteira de clientes, satisfação e volumes depositados pelos clientes atuais (perspectiva dos clientes); e obter informações financeiras acerca da empresa (perspectiva financeira).

Diante dos objetivos apresentados, espera-se que a empresa possa buscar e alcançar a sua visão, sendo reconhecida pelos seus clientes e colaboradores pela qualidade e transparência de suas relações dentro do agronegócio no Estado do Rio Grande do Sul. Como limitações do trabalho desenvolvido destaca-se, primeiramente, que para essa pesquisa utilizou-se uma adaptação do modelo do BSC e não a sua metodologia na íntegra. Salienta-se, também, que a falta de informações sobre concorrentes não possibilitou uma análise mais completa acerca destes, bem como o período de safra ter limitado o acesso a algumas informações.

Ressalta-se ainda a inexistência de uma cultura propícia à implantação de um planejamento estratégico dentro da empresa, o que dificultou diversas etapas do estudo. Ao findar essa análise, recomenda-se que seja dada continuidade a esta pesquisa na Alpha Insumos Agrícolas com a implantação e execução dos planos de ação traçados e, ainda, o acompanhamento das atividades através dos indicadores de desempenho.

Além disso, diante da forte competitividade no atual ambiente de negócios, sugere-se a elaboração do planejamento estratégico em organizações do mesmo setor de atividades, adequando suas ações e planos em conformidade com a sua realidade empresarial. E, após isso, é importante também que seja realizada periodicamente uma medição dos resultados, bem como uma avaliação do desempenho, fazendo os devidos ajustes sempre que necessário.

\section{Referências}

ALMEIDA, L.; MIGUEL, P. C.; CARVALHO, M. M. de. Aplicação do gerenciamento de projetos no processo de desenvolvimento de novos produtos - um caso exploratório. Revista de Gestão e Projetos, São Paulo, v. 2, n. 2, p. 77-101, jul./dez. 2011.

ARANTES, G. R. de. Análise do processo de implantação do balanced scorecard: o caso do painel corporativo de uma empresa brasileira do se- 
tor público. 2006. 117f. Dissertação de Mestrado (Administração Pública) - Escola Brasileira de Administração Pública da Fundação Getúlio Vargas, Rio de Janeiro, 2006.

BACK, L.; DUTRA, A.; CASAGRANDE, J. L. Estruturação do balanced scorecard - BSC, para uma empresa do segmento varejista, com foco na avaliação do desempenho da ação estratégica de marketing promocional. ConTexto, Porto Alegre, v. 12, n. 22, p. 7-25, 2012.

CASTRO, A. de; SOUSA, J. C. B. de; CATAPAN, E. A.; CATAPAN, A.; CATAPAN, D. C. Mapa estratégico: as perspectivas do balanced scorecard no alinhamento do planejamento estratégico com o planejamento orçamentário. Revista Espacios, Venezuela, v. 36, n. 7, p. 15-23, 2015.

EL-KOUBA, A.; ROGLIO, K. de D.; DEL CORSO, J. M.; SILVA, W. V. da. Programas de desenvolvimento comportamental: influências sobre os objetivos estratégicos. Revista de Administração de Empresas, São Paulo, v. 49, n. 3, p. 295-308, jul./set. 2009.

FELIXAN, A. G.; SILVA, S. W.; MAGALHÃES, S. R. A satisfação de clientes na indústria de refratários. Revista de Iniciação Científica da Universidade Vale do Rio Verde, Três Corações, v. 2, n. 2, p. 3-13, 2012.

FERREIRA, F.; DIEHL, C. A. Perfil da produção científica brasileira sobre balanced scorecard. Revista Eletrônica Estratégia \& Negócios, Florianópolis, v. 6, n. 1, p. 54-88, jan./abr. 2013.

FREIRE, L. C. M.; DALTO, E. J. Sistema de informação para classificação de clientes. Revista Eletrônica de Sistemas de Informação, Campo Largo, v. 7, n. 1, p. 1-12, 2008.

FUNDAÇÃO NACIONAL DA QUALIDADE. Indicadores de desempenho - estruturação do sistema de indicadores organizacional. 3. ed. São Paulo: Fundação Nacional da Qualidade, 2012.

HERNANDES, C. A. M; CRUZ, C. S. da.; FALCÃO, S. D. Combinando o balanced scorecard com a gestão do conhecimento. Caderno de
Pesquisas em Administração, São Paulo, v. 1, n. 12, 2000.

KAPLAN, R. S.; NORTON, D. P. A estratégia em ação: balanced scorecard. Rio de Janeiro: Campus, 1997.

; __ _. Organização orientada para a estratégia: como empresas que adotam o balanced scorecard prosperam no novo ambiente de negócios. 4. ed. Rio de Janeiro: Campus, 2001.

LIMA, S. R. A.; MOREIRA, J. W. S.; FONTENELE, M. G.; CRUZ, M. A. P. da. A influência da comunicação interna na produtividade. Revista Inova Ação, Teresina, v. 1, n. 2, art. 2, p. 18-29, jul./dez. 2012.

MACCARI, E. A.; LOBOSCO, A.; SOUZA, N. de. A importância da ferramenta balanced scorecard para análise financeira da empresa - um estudo de caso na empresa Duratex. In: SEMINÁRIOS EM ADMINISTRAÇÃO, 12., São Paulo, 2012. Anais... São Paulo: SEMEAD, 2012.

MINISTÉRIO DA AGRICULTURA, PECUÁRIA E ABASTECIMENTO. Balança comercial do agronegócio - abril/2015. Disponível em: <http://www.agricultura.gov.br/arq_editor/Nota \%20Abril\%202015.pdf>. Acesso em: 20 jun. 2015.

MÜLLER, C. J. Modelo de gestão integrando planejamento estratégico, sistemas de avaliação de desempenho e gerenciamento de processos (MEIO - Modelo de Estratégia, Indicadores e Operações). 2003. 292 f. Tese (Doutorado em Engenharia) - Escola de Engenharia, Universidade Federal do Rio Grande do Sul, Porto Alegre, 2003.

RAMIRES, R. M. C. Modelo de balanced scorecard focado em aprendizagem e crescimento: o caso da INETCOMM, agente exclusivo da OI. 2010. 95 f. Trabalho de Conclusão de Curso (Graduação em Administração) - Departamento de Ciências Administrativas da Universidade Federal do Rio Grande do Sul, Porto Alegre, 2010. 
OLIVEIRA, D. de P. R. de. Estratégia empresarial \& vantagem competitiva. 8. ed. São Paulo, Atlas, 2011.

PADOVEZE, C. L. Controladoria estratégica e operacional. 3. ed. São Paulo: Cengage Learning, 2012.

PEARSALL, M. Participant observation as role as method in behavioral research. Nursing Research, New York, v. 14, n. 1, 1968.

PRIETO, V. C.; PEREIRA, F. L. A.; CARVALHO, M. M. de; LAURINDO, F. J. B. Fatores críticos na implementação do balanced scorecard. Gestão \& Produção, São Carlos, v. 13, n. 1, p. 81-92, jan./abr. 2006.

PRODANOV, C. C.; FREITAS, E. C. de. Metodologia do trabalho científico: métodos e técnicas da pesquisa e do trabalho acadêmico. 2. ed. Novo Hamburgo: Feevale, 2013.

SILVA, A. C. da; LIMA, E. P. C. de; BATISTA, H. R. A importância da soja para o agronegócio brasileiro: uma análise sob o enfoque da produção, emprego e exportação. In: ENCONTRO DE ECONOMIA CATARINENSE, 5., Florianópolis, 2011. Anais... Florianópolis: EEC, 2011.

SILVA, L. C. da. O balanced scorecard e o processo estratégico. Caderno de Pesquisas em Administração, São Paulo, v. 10, n. 4, p.61-73, out./dez. 2003.

SILVA, S. V. da; PORTUGAL, N. dos; SOUZA, A. A. de P. A adaptação do balanced scorecard ao sinaes: um estudo de caso em uma instituição de ensino superior privada. In: SEMINÁRIOS EM ADMINISTRAÇÃO, 17., São Paulo, 2014. Anais... São Paulo: SEMEAD, 2014.

SOARES, W. L. P.; SIMÕES JUNIOR, J.; TINOCO, J. E. P. Os indicadores financeiros do $b a-$ lanced scorecard - BSC na gestão de transporte multimodal. Revista Eletrônica Patrimônio: Lazer \& Turismo, Santos, v. 7, n. 9, p. 97-114, jan./fev./mar. 2010.
TAVARES, M. C. Gestão estratégica. 3. ed. São Paulo: Atlas, 2010.

VILLA, D. A.; LERMEN, F. H.; LUDEWIG, D. R.; CAMPOS, R. V. de M. Mapeamento estratégico para uma indústria de papel utilizando a metodologia do balanced scorecard (BSC). In: CONGRESSO INTERNACIONAL DE ADMINISTRAÇÃO, 26., Ponta Grossa, 2013. Anais... Ponta Grossa: CONGRESSO ADM, 2013.

VOLPE, R. A.; LORUSSO, C. B. A importância do treinamento para o desenvolvimento do trabalho. Psicologia, Online, p. 1-8, 2009.

WILLYERD, K. A. Balancing your evaluation act. Training, n. 34, 1997.

ZEUS, C. Balanced scorecard com ênfase na importância corporativa e social. Revista Brasileira de Contabilidade, ano XXXIII, n. 148, 2004. 